BMJ Open Sport \& Exercise Medicine

\title{
Recommendations for return to sport during the SARS-CoV-2 pandemic
}

Herbert Löllgen, ${ }^{1}$ Norbert Bachl, ${ }^{1,2,3,4}$ Theodora Papadopoulou, ${ }^{1,4,5,6}$

Andrew Shafik, ${ }^{7,8}$ Graham Holloway, ${ }^{5}$ Karin Vonbank, ${ }^{9}$ Nigel Edward Jones, ${ }^{5,10,11}$

Xavier Bigard, ${ }^{1,4,12}$ David Niederseer (D) , ${ }^{13}$ Joachim Meyer, ${ }^{14}$

Borja Muniz-Pardos (D) , ${ }^{15}$ Andre Debruyne, ${ }^{1,4}$ Petra Zupet, ${ }^{1,4,16}$

Jürgen M Steinacker (D) , 1,4,17 Bernd Wolfarth, ${ }^{4,18}$ James Lee John Bilzon (D) ,,5,19

Anca lonescu, ${ }^{1}$ Michiko Dohi (D) , ${ }^{4,20}$ Jeroen Swart (D) ,,21

Victoriya Badtieva (1) , 4,22,23 Irina Zelenkova, ${ }^{15,22}$ Maurizio Casasco, ${ }^{1,4,24}$

Michael Geistlinger, ${ }^{4,25}$ Luigi Di Luigi (10) , ${ }^{4,26}$ Nick Webborn, ${ }^{27,28}$ Patrick Singleton, ${ }^{29}$

Mike Miller, ${ }^{29}$ Fabio Pigozzi, ${ }^{1,4,30,31}$ Yannis P Pitsiladis (10) 1,4,32

\section{ABSTRACT}

In this viewpoint we make specific recommendations that can assist and make the return to sport/exercise as safe as possible for all those impacted - from the recreational athlete to the elite athlete. We acknowledge that there are varying rules and regulations around the world, not to mention the varying philosophies and numerous schools of thought as it relates to return to sport/exercise and we have been cognisant of this in our recommendations. Despite the varying rules and circumstances around the world, we believe it is essential to provide some helpful and consistent guidance for return to training and sport for sport and exercise physicians around the world at this most difficult time. The present viewpoint provides practical and medical recommendations on the resumption to sport process.

\section{BACKGROUND}

The COVID-19 pandemic and the restrictive measures adopted internationally in order to contain the virus has led to a disruption of organised sport at all levels. During the lockdown period, outdoor exercise was forbidden or partly restricted in some cases without access to sports facilities including gyms or sports centres. As the number of infections and hospitalisations decreased, the strict lockdown was gradually lifted. Team sports have commenced reintroducing their training routines in groups, and the Bundesliga reactivated the professional league behind closed doors on 16 May 2020 despite serious concerns raised by some in the scientific community. ${ }^{1}$ Additional sporting competitions such as boxing, Ultimate Fighting Championship and Formula 1 are also scheduled to resume. ${ }^{2}$ It is worth noting that social distancing is possible in some sports (eg, tennis, swimming, athletics and golf) whereas this is not always possible in other cases (eg, football, rugby, basketball, cycling and boxing), and careful measures of hygiene and control are especially needed for these more at risk sports to regulate the safety of sport resumption and to avoid possible infections. For more thorough information about the risk factors and symptoms to be considered to make the return to sport as safely as possible, consult Carmody et $a l^{3}$ and Nieß et $a l^{4}$. The present viewpoint provides practical and medical recommendations on the resumption to sport process.

\section{GROUP IDENTIFICATION}

During the resumption to sport process, the following groups must be distinguished (individuals below refer to both leisure time and professional athletes or persons starting new with regular physical activities). This group classification is a more developed version of that recently published by Phelan $e t a l^{5}$ :

1. Individuals without symptoms and signs that never have been tested positive for severe acute respiratory syndrome coronavirus 2 (SARS-CoV-2).

2. Individuals with a positive SARS-CoV-2 test without any COVID-19 symptoms but isolating at home (quarantine) under close medical observation (telephonic or video).

3. Individuals who experienced COVID-19 with mild symptoms, only needing outpatient treatment and quarantine for 14 days.

4. Individuals with moderate symptoms but had inpatient treatment due to an increased risk derived from pre-existing conditions (eg, asthma, diabetes).

5. Individuals with severe symptoms, inpatient treatment, including intensive care without artificial respiration. 
6. Individuals with severe symptoms, inpatient treatment in intensive care and on artificial respiration.

It is imperative that a medical examination is performed in cooperation with a respiratory physician and/or cardiologist, if suspicious findings of the pulmonary and/or cardiovascular systems arise.

\section{RECOMMENDATIONS FOR INDIVIDUAL GROUPS Group 1}

In individuals without symptoms and signs of COVID-19 and without any pre-existing medical condition(s), risk stratification to safely resume to sport has to be evaluated through questionnaires compiling data related to personal and medical history, close contact with people with positive SARS-CoV-2 test, or contact with people of high risk of having been infected without being tested positive, or in so called hotspots. The individual has to confirm being free of any symptoms and this must be documented. Exercise testing is likely to be necessary in some sports due to the expected detraining after lockdown, ${ }^{6}$ and exercise testing must be performed according to the latest COVID-19/SARS-CoV-2 health and safety regulations.

\section{Group 2}

Resumption after 14 days quarantine. Examinations ought to include medical history, physical examination, 12-channel ECG, lung function assessment with typical respiratory signs and symptoms, and ECG stress test. ${ }^{5-9}$ Echocardiography if clinically indicated.

\section{Group 3}

Resumption after a quarantine period of 2 weeks and strict social distancing for another 2 weeks.

A medical examination by a sport and exercise medicine physician with medical history, physical examination, blood test focused on critical markers (eg, C-reactive protein, high sensitivity troponin-I, natriuretic peptides), and resting ECG (eg, changes of Q-wave, ST-stretch, T-wave) ${ }^{8}$ Additional lung function assessment and stress test with ECG, blood gas analysis and spiroergometry as well as echocardiography are recommended if symptoms have involved respiratory or cardiac impairment. Return to regular sport is possible 3-4weeks after beginning of the symptoms under medical surveillance for 6 months after return to sport if any symptoms are present but not limiting return to sport.

\section{Group 4}

Same procedure as for group 3 but including compulsory ergometry with blood gas analysis and/or spiroergometry. ${ }^{3-5} 10$ Chest X-ray examination and depending on the findings obtained during the inpatient stay, highresolution CT of the thorax in the most severe cases always in consultation with a lung specialist. Cardiac examinations depending on medical history, symptoms and signs, cardio-MRI after consultation with a cardiologist. Return to sport will vary from 2 to 6 months depending on the severity of respiratory (lung) and/or cardiac (myocarditis) involvement.

\section{Groups 5 and 6}

Following SARS-CoV-2 discharge, rehabilitation is recommended. A complete pulmonary and cardiological examination is necessary ('cardiac markers' such as high sensitivity troponin-I or natriuretic peptides) including resting ECG, lung function, echocardiography, stress test with ECG and blood gas analysis. ${ }^{810-13}$ Return to sport will be after several months depending on the severity and completeness of recovery.

Depending on previous findings in heart rate, CT of the thorax and cardiac MRI examination in consultation with a respiratory physician and cardiologist, hospital discharge can take place. A final medical check and sports statement is mandatory.

Resumption of sport can occur 10-14 days after complete recovery from SARS CoV-2 infection for athletes included in groups 1 and 2. In patients with more severe organ involvement, pneumonia, myocarditis or neurological signs, an individualised plan is necessary. ${ }^{45}$ Testing for SARS CoV-2 can be carried out to support a return to play decision but is not essential unless stipulated (eg, National/International Sports Federation, Government).

\section{CONCLUSIONS}

An adequate assessment of the resumption of sporting activity is based on a case-by-case decision that must consider the individual situation of the athlete including pre-existing conditions, the type of sport and the risk of infection from other athletes (eg, increased risk in contact/team sports). The recommendation to return to play will be based on the results of the examination and individual assessment in consultation with the sport and exercise medicine physician, specialists in pulmonary medicine and sport cardiology (or extended multidisciplinary team), coaches and training specialists. After a contact ban, an athlete should be provided with recommendations on sports resumption that are in accordance with national and regional guidelines. After a longer period of interruption in sport caused by more severe health issues, increases in training should be gradual and individualised by monitoring signs and symptoms of the health issue.

\section{Author affiliations}

${ }^{1}$ European Federation of Sports Medicine Associations (EFSMA), Lausanne, Switzerland

${ }^{2}$ Institute of Sports Science, University of Vienna, Vienna, Austria

${ }^{3}$ Austrian Institute of Sports Medicine, Vienna, Austria

${ }^{4}$ International Federation of Sports Medicine (FIMS), Lausanne, Switzerland

${ }^{5}$ British Association of Sport and Exercise Medicine, Doncaster, UK

${ }^{6}$ Defence Medical Rehabilitation Centre, Loughborough, UK

${ }^{7}$ South Tyneside NHS Foundation Trust, Sunderland, UK

${ }^{8}$ Newcastle Thunder Rugby, Newcastle, UK

${ }^{9}$ Department of Pneumology, Pulmonary Function Laboratory, Medicine Clinic (KIMII), University of Vienna, Vienna, Austria

${ }^{10}$ British Cycling, Manchester, UK 
${ }^{11}$ University of Liverpool, Liverpool, UK

${ }^{12}$ Union Cycliste Internationale (UCl), Aigle, Switzerland

${ }^{13}$ Heart Centre, University of Zurich, Zurich, Switzerland

${ }^{14}$ Lung Center, Clinic Bogenhausen, Munich, Germany

${ }^{15} \mathrm{GENUD}$ (Growth, Exercise, Nutrition and Development), University of Zaragoza, Zaragoza, Spain

${ }^{16}$ Institute of Medicine and Sports, Ljubljana, Slovenia

${ }^{17}$ Division of Sports and Rehabilitation Medicine, Ulm University Hospital, Ulm, Germany

${ }^{18}$ Department of Sport Medicine, Humboldt University and Charité University School of Medicine, Berlin, Deutschland, Germany

${ }^{19}$ Department for Health, University of Bath, Bath, UK

${ }^{20}$ Sport Medical Center, Japan Institute of Sports Sciences, Tokyo, Japan

${ }^{21}$ UCT Research Unit for Exercise Science and Sports Medicine, University of Cape Town (UCT), Cape Town, South Africa

${ }^{22}$ I.M. Sechenov First Moscow State Medical University (Sechenov University), Moscow, Russian Federation

${ }^{23}$ Moscow Research and Practical Centre for Medical Rehabilitation, Restorative and Sports Medicine, Moscow Healthcare Department, Moscow, Russian Federation ${ }^{24}$ Italian Federation of Sports Medicine (FMSI), Rome, Italy

${ }^{25}$ Unit International Law, Department of Constitutional, International and European Law, University of Salzburg, Salzburg, Austria

${ }^{26}$ Unit of Endocrinology, Department of Movement, Human and Health Sciences, University of Rome "Foro Italico", Rome, Italy

${ }^{27}$ School of Sport and Service Management, Eastbourne, UK

${ }^{28}$ School of Sport, Exercise and Health Sciences, Loughborough University, Loughborough, UK

${ }^{29}$ World Olympians Association, Lausanne, Switzerland

${ }^{30}$ University of Rome "Foro Italico", Rome, Italy

${ }^{31}$ FIFA Medical Center of Excellence, Villa Stuart Sport Clinic, Rome, Italy

${ }^{32}$ Collaborating Centre of Sports Medicine, University of Brighton, Eastbourne, UK

Twitter David Niederseer @DavidNiederseer

Contributors All authors contributed significantly to merit publication and in accordance with the BJSM instructions to authors.

Funding The authors have not declared a specific grant for this research from any funding agency in the public, commercial or not-for-profit sectors.

Competing interests None declared.

Patient consent for publication Not required.

Provenance and peer review Not commissioned; externally peer reviewed.

Open access This is an open access article distributed in accordance with the Creative Commons Attribution Non Commercial (CC BY-NC 4.0) license, which permits others to distribute, remix, adapt, build upon this work non-commercially, and license their derivative works on different terms, provided the original work is properly cited, appropriate credit is given, any changes made indicated, and the use is non-commercial. See: http://creativecommons.org/licenses/by-nc/4.0/.

\section{ORCID iDs}

David Niederseer http://orcid.org/0000-0003-3089-1222

Borja Muniz-Pardos http://orcid.org/0000-0002-9191-9033

Jürgen M Steinacker http://orcid.org/0000-0001-8901-9450
James Lee John Bilzon http://orcid.org/0000-0002-6701-7603

Michiko Dohi http://orcid.org/0000-0002-1126-7849

Jeroen Swart http://orcid.org/0000-0001-7098-0313

Victoriya Badtieva http://orcid.org/0000-0003-4291-679X

Luigi Di Luigi http://orcid.org/0000-0002-2522-126X

Yannis P Pitsiladis http://orcid.org/0000-0001-6210-2449

\section{REFERENCES}

1 Corsini A, Bisciotti GN, Eirale C, et al. Football cannot restart soon during the COVID-19 emergency! A critical perspective from the Italian experience and a call for action. Br J Sports Med 2020 doi:10.1136/bjsports-2020-102306. [Epub ahead of print: 24 Mar 2020].

2 Coronavirus and sports: what happened in April 2020 | Sports| German football and major international sports news | DW | 01.05.2020. Available: https://www.dw.com/en/coronavirus-sportscancellations/a-52569936 [Accessed 8 May 2020].

3 Carmody S, Murray A, Borodina M, et al. When can professional sport recommence safely during the COVID-19 pandemic? risk assessment and factors to consider. Br J Sports Med 2020. doi:10.1136/bjsports-2020-102539. [Epub ahead of print: 07 May 2020].

4 Nieß AM, Bloch W, Friedmann-Bette B, et al. Position stand: return to Sport in the Current Coronavirus Pandemic (SARS-CoV-2/ COVID-19). Ger J Sport Med 2020;71:E1-4.

5 Phelan D, Kim JH, Chung EH. A game plan for the resumption of sport and exercise after coronavirus disease 2019 (COVID-19) infection. JAMA Cardiol 2020. doi:10.1001/jamacardio.2020.2136. [Epub ahead of print: 13 May 2020].

6 Pillay L, Janse van Rensburg DCC, Jansen van Rensburg A, et al. Nowhere to hide: the significant impact of coronavirus disease 2019 (COVID-19) measures on elite and semi-elite South African athletes. J Sci Med Sport 2020;23:670-9.

7 Schellhorn P, Klingel K, Burgstahler C. Return to sports after COVID-19 infection. Eur Heart J 2020. doi:10.1093/eurheartj/ ehaa448. [Epub ahead of print: 20 May 2020].

8 Bhatia RT, Marwaha S, Malhotra A, et al. Exercise in the Severe Acute Respiratory Syndrome Coronavirus-2 (SARS-CoV-2) era: A Question and Answer session with the experts Endorsed by the section of Sports Cardiology \& Exercise of the European Association of Preventive Cardiology (EAPC). Eur J Prev Cardiol 2020;20474873 2093059:2047487320930596.

9 Kirkpatrick JN, Mitchell C, Taub C, et al. Ase statement on protection of patients and echocardiography service providers during the 2019 novel coronavirus outbreak: endorsed by the American College of cardiology. J Am Coll Cardiol 2020;75:3078-84.

10 Atri D, Siddiqi HK, Lang JP, et al. COVID-19 for the cardiologist: basic virology, epidemiology, cardiac manifestations, and potential therapeutic strategies. JACC basic to trans/ Sci 2020;5:518-36.

11 Barker-Davies RM, O'Sullivan O, Senaratne KPP, et al. The Stanford Hall consensus statement for post-COVID-19 rehabilitation. $\mathrm{Br} J$ Sports Med 2020. doi:10.1136/bjsports-2020-102596. [Epub ahead of print: 31 May 2020].

12 Szekely Y, Lichter Y, Taieb P, et al. The Spectrum of Cardiac Manifestations in Coronavirus Disease 2019 (COVID-19) - a Systematic Echocardiographic Study. Circulation 2020. doi:10.1161/ CIRCULATIONAHA.120.047971. [Epub ahead of print: 29 May 2020].

13 Dores H, Cardim N. Return to play after COVID-19: A sport cardiologist's view. Br J Sports Med 2020. 